\title{
La recepción del pensamiento agustiniano sobre el tiempo en Temps et récit de Paul Ricœur
}

\author{
Rodrigo Álvarez Gutiérrez, OSB \\ MONASTERIO BENEDICTINO SANTÍSIMA TRINIDAD \\ ralvareg@uc.cl
}

\section{Preámbulo}

La temporalidad constituye una vertiente de reflexión tanto para el hombre del pasado como del presente. Por ello, Agustín de Hipona en el Libro XI de las Confesiones desarrolla el binomio tiempo-eternidad ${ }^{1}$.

La alabanza bíblica ${ }^{2}$ es el medio para abordar la actuación divina extramundana. Sin embargo, qué sucede con el tiempo; y más aún cuando la eternidad se reviste de cronos en Jesucristo ${ }^{3}$. El Doctor de la Gracia se resiste a la medición y al movimiento como claves para entender esta pregunta. Para ello, se aleja de la distinción clásica del tiempo:

"Pretérito, presente y futuro; sino que tal vez sería más propio decir que los tiempos son tres: presente de las cosas pasadas, presente de las cosas presentes y presente de las futuras. Porque estas son tres cosas que

1 Cfr. E. Przywara, Augustin passions et destins de l'Occident (Les Éditions du Cerf, Paris 1987).

2 Cfr. A. La Coque - P. Ricceur, Pensar la Biblia (Herder, Barcelona 2001). Cfr. D. Nocquet, "La grande chronologie: temps et espace dans le récit biblique de l'histoire" en Etudes theologiques et religieuses 85 (2010), 420-421.

3 Cfr. L. Gioia, The theological Epistemology of Augustine's de Trinitate (Oxford Theological Monographs, Oxford 2010), 68ss. Cf. L. GioiA, "La connaissance du Dieu Trinité chez Saint Agustín, par delà les embarras de l'analogie et de l'anagogie" en E. Durand - V. Holzer (ed.), Les sources du renouveau de la théologie trinitaire au XXe siècle, Colección Cogitatio Fidei 266 (Les Éditions du Cerf, Paris 2008), 97-139. Cfr. B. Studer, The Grace of Christ and the Grace of God in Augustine of Hippona: Christocentrism or Theocentrism? (The Liturgical Press, Collegeville 1997). Cfr. W. $\mathrm{KNOCH}$, Dieu à la recherche de l'homme (Éditions du Cerf, Paris, 1995). 
existen de algún modo en el alma, y fuera de ella yo no veo que existan: presente de cosas pasadas (la memoria), presente de cosas presentes (visión) y presente de cosas futuras (expectación)"’4.

Es así como la condición ontológica del tiempo ${ }^{5}$ se transforma en dimensión psicológica del mismo. Por ello, las interrogantes ¿qué es, pues, el tiempo? ¿Quién podrá explicar esto fácil y brevemente? ${ }^{6}$, permanecieron sin responder en la especulación inmediata ${ }^{7}$. La cosmogonía tradicional no logra integrar a uno de sus personajes principales: el hombre. Solo con la figura de Husserl y Heidegger, el tiempo vuelve a la palestra intelectual ${ }^{8}$.

Por su parte, Paul Ricœur en Temps et récit retoma la disquisición de Agustín desde la mediación del relato: "La función referencial de la trama reside precisamente en la capacidad que tiene la ficción de refigurar esta experiencia temporal víctima de las aporías de la especulación". El tiempo es tratado como una vivencia recreada y no como un intento de llegar a la quidditas del objeto. Pese a ello, la intentio y la distensio animi son conceptos recurrentes en la misma argumentación de Ricœur; pero desde el concepto de ipseidad. Tanto Agustín como Aristóteles se encuentran

4 San Agustín, Las Confesiones (BAC, Madrid MCMLXXIX), XI, 20,26: "tempora sun tria: presens de praeteritis, praesen de praesentibus, presens de futuris. Sunt enim haec in anima tria quaedam et alibi ea non video, praesen de praeteritis memoria, praesens de praesentibus contuitus, praesens de futuris expectatio".

5 Cfr. I. Chareire, "Note sur le paradoxe chrétien du rapport au temps" en Théophilyon, 15 (2010), 175-188. Cfr E. Brito, "Le temps: énigme des hommes, mystère de Dieu” en Ephemerides theologicae Lovanienses, 83 (2007), 529. Cfr. R. Johann, "Le mystère du temps: Approche théologique" en Theological Studies 24(1963), 324-325.

6 San Agustín, Confesiones XI, 14,17: "Quid est enim tempus? Quis hoc fáciles breviterque explicaverit?".

7 Cfr. J. Pegueroles, San Agustín un platonismo agustiniano (PPU, Barcelona 1985), 168-182. Cfr. S. BöHn, La temporalité dans l'anthropologie augustinienne (Les Éditions du Cerf, Paris 1984), 15-94.

8 Cfr. E. Housset, Husserl et l'idée de Dieu (Éditions du Cerf, Paris 2010), 71-106. Cfr. P. Y. Bourol, Le Dieu des philosophes (Éditions du Cerf, Paris 1989).

9 P. Ricceur, Tiempo y narración I (Siglo XXI, Madrid 1997), 34: “c'est dans la capacité de la fiction de re-figurer cette expérience temporelle en proie aux apories de la spéculation philosophique que réside la fonction référentielle de l'intrigue". La traducción francesa ocupada es: P. Ricceur, Temps et récit I (Éditions du Seuil, Paris 1983), 13. En adelante, pondremos entre paréntesis la página correspondiente al final de la cita original francesa. 
en núcleos esenciales de la argumentación del filósofo francés. ¿Cuál es la intención de ello? A simple vista se podría hablar de un uso de fuentes, influencia o de recepción. Hans Urs von Balthasar ${ }^{10}$ afirmaba que la distensión del alma en Agustín constituye una condición previa a la experiencia del tiempo, constituyendo a la psique como medio referencial al igual que la función narrativa. Es así como la hermenéutica realizada por Paul Ricœur se torna compleja con el paso de lo simbólico a lo textual ${ }^{11}$.

Por lo cual, se hace necesario estudiar el tratamiento que hace Paul Ricœur de la temporalidad agustiniana, pues su pensar es dialogal y conlleva un fin. Este es el paso de la relación: tiempo-narración a "tiempo narrado". Centraremos nuestra atención en el capítulo 1 del tomo I de Temps et récit: "Aporías de la experiencia del tiempo: el libro XI de las Confesiones de san Agustín" y el capítulo 1 del tomo III: "Tiempo del alma y tiempo del mundo: el debate entre Agustín y Aristóteles". Este último apartado se abocará solo a la relación Agustín-Ricœur, dejando de lado a Aristóteles pues nuestro estudio rebasaría los límites propuestos.

\section{La reconstrucción argumentativa de Paul Ricoeur del tema temporal del libro XI de las Confesiones}

Son conocidos los numerosos estudios sobre la relación de Paul Ricœur y Agustín. Cabe mencionar a Isabelle Bochet ${ }^{12}$, L. Alici ${ }^{13}$, D. Capps ${ }^{14}, \mathrm{G}$

10 Cfr. H. U. Von Balthasar, El todo en el fragmento (Ediciones Encuentro, Madrid 2008), 23.

11 Jean Greisch señala los grandes lineamientos del pensar religioso de P. Ricœur. Para mayor información Cfr. PH. Capelle-Dumont, Philosophie et théologie à l'époque contemporaine, $I V$, Jean Greisch-Geneviève Hébert (ed.) (Éditions du Cerf, Paris 2011), 235-246.

12 Cfr. I. Bochet, Augustin dans la pensée de Paul Ricœur (Éditions Facultés Jésuites de Paris, Paris 2003), 39 ss. Cfr. I. Bochet, Saint Augustin et le désir de Dieu (ÉtudesAugustiniennes, Paris 1982). 118 ss. Cfr. I. Bochet, "Variations contemporaines sur le thème augustinienne: l'énigme du temps" en Maxence Caron (ed.) Les cahiers d'histoire de la philosophie: saint Augustin saint Augustin (Éditions du Cerf, Paris 2009) 519-549.

13 L. Alici, "Temporalità e memoria nelle Confessiones. L'interpretazione di Paul Ricœur" en Augustinus 39(1994), 5-19.

14 D. Capps, "Augustine as Narcissist: Comments on Paul Rigby's Paul Ricœur, Freudianism and Austine's Confessions" en Journal of the American Academy of religion 53 (1985), 125-127. 
Madec $^{15}$ y J. Wilson ${ }^{16}$. Cada uno de ellos aborda algún aspecto de dicha reciprocidad.

El tema de la temporalidad ocupa un puesto relevante en la investigación del autor francés, la cual muchas veces va acompañado de la memoria, la historia y el olvido ${ }^{17}$. Sin embargo, no se puede dejar de lado la pertinencia de su lectura agustiniana, la cual se circunscribe en el enig$\mathrm{ma}^{18}$ del libro XI ¿Cómo es posible que el Doctor de la Gracia pase de un relato autobiográfico a comentar el libro del Génesis? A lo anterior hay que agregar el tópico de la mensurabilidad del tiempo y la función de la memoria. Pareciera que el autor francés olvidara asuntos tan relevantes de la lógica agustiniana. Este, en Caminos de reconocimiento, señalará: "La problemática del reconocimiento de sí alcanza simultáneamente dos cimas con la memoria y la promesa [...] Pero ambas deben pensarse juntas en el presente vivo del reconocimiento de sí, gracias a algunos rasgos que poseen en común"19.

Es así como Ricœur apunta a un hecho fundamental. Agustín no pretende afirmar qué es el tiempo, sino conducir al lector a la trascendencia divina. Por su parte, el autor francés busca puntos de mediación.

La ya mencionada profesora Bochet confecciona, en su libro titulado Augustin dans le pensée de Paul Ricœur, un índice de los textos agustinianos comentados por dicho autor. Las Confesiones son las que poseen el mayor número de frecuencias, destacando el libro XI. ¿Cuál será el interés por estas páginas? Es indudable que el tópico del tiempo y de la memoria atraviesan gran parte de la obra ricqueriana. Pero en Temps et récit subyace el quomodo de una conjunción. Este es el "et". ¿Cuál es la intención de este título? Pensada de modo ingenuo podría significar

15 G. Madec, "Ricœur Paul, Temps et Récit, I" en Bulletin augustinien, Revue des Études Augustiniennes 30 (1984), 373-374.

16 J. Wilson, Converting Time en Contemporary Philosophy 15 (1993), 19-23.

17 Cabe mencionar: Histoire et vérité, La mémoire, l'histoire, l'oubli, La métaphore vive, Le conflit des interprétations como las más relevantes en el análisis de estos temas.

18 Cfr. I. Bochet, "Variations contemporaines sur le thème augustinienne: l'énigme du temps" en Les cahiers d'histoire de la philosophie: saint Augustin, 525ss. Esta autora explica la cuestión señalando que el libro XI afirma a Dios como creador, el libro XII que la mutación de las cosas constituye el tiempo y el libro XIII distingue el tiempo del alma del tiempo del mundo.

19 P. Ricceur, Caminos de reconocimiento (FCE, México, 2006), 145. 
el estudio de dos realidades equiparables o distintas. Pero Paul Ricœur establece una tesis de trabajo donde se presentan dos elementos en juego. Por un lado el lenguaje narrado (vivido) y por otro la temporalidad. Este afirmará: "El mundo desplegado por toda obra narrativa es siempre un mundo temporal" ${ }^{20}$. Es así como la materialidad de la escritura posee una virtualidad creadora. Se podría llamar performativa, es decir, la palabra constituye realidad. Pero ¿qué sucede con el tiempo? ¿Se contradice con la narración o se complementa con él? Nuestro autor dirá: "[...] la narración es significativa en la medida en que describe los rasgos de la experiencia temporal" 21 . El presupuesto implica una cópula verbal. Un mundo equivale al otro desde una lógica clásica. Pero no nos encontramos ante una premisa que implica igualdad, sino significatividad. La semántica del tiempo y de la narración involucran una hermenéutica circular en el sentido pleno del término.

El tiempo requiere una modalidad antropológica de funcionamiento, el cual es dado por la narración y el lector que le acompaña. A su vez, todo discurso narrativo es significativo por su carácter sincrónico-diacrónico.

Teniendo presente lo anterior, se podría sostener que el modus operandi de Ricœur implica la complementariedad de dichas afirmaciones y no su dependencia viciosa. Este se vale de dos ejes agustinianos para validar la necesidad de dicha propuesta:

a) El tiempo humano y la eternidad divina

b) El tiempo como intentio y distentio animi.

Es así como nos encontramos con un lector de Agustín que busca significatividad y respuestas inconclusas, no soluciones. De ninguna forma el mundo del lector violenta el relato en sí. Paul Ricœur abre, revela y manifiesta el mundo agustiniano. Ahondaremos cómo realiza esta labor.

\subsection{Tiempo humano y eternidad divina}

Este binomio constituye el principio de una reflexión que no desechará las características más evidentes del texto agustiniano. Ya sea por el

20 P. Ricceur, Tiempo y narración I, 39: "Le monde déployé par toute œuvre narrative est toujours un monde temporel" (17).

21 P. Ricceur, Tiempo y narración I, 39: “[...] le récit est significatif dans la mesure ou il dessine les traits de l'expérience temporelle" (17). 
contexto religioso dado por el hecho teológico de la creación. Bernard Rey acotará: "En efecto, decir que Dios crea la luz, las estrellas, la tierra y todo lo que contiene, y en última instancia, la humanidad significa que desacraliza estas realidades: no son más que criaturas [...] Dios es el creador, el pueblo elegido lo distingue de todo el orden creado: Él es totalmente distinto de su creación"22 ya sea por el tono himnódico del mismo. J. L. Marion señalará: "Reconocemos en primer lugar e inmediatamente el principio que para Agustín la confessio se divide en la confesión de los pecados y una confesión de alabanza”23. Es así como el mismo Agustín afirma:

"Por ventura, Señor, siendo tuya la eternidad, ignoras las cosas que te digo, o ves en el tiempo lo que se ejecuta en el tiempo? Pues, ¿por qué te hago relación de tantas cosas? No ciertamente para que las sepas por mí, sino que excito con ellas hacia ti mi afecto y el de aquellos que leyeren estas cosas, para que todos digamos: Grande es el Señor y laudable sobremanera. Ya lo he dicho y lo diré: por amor de tu amor hago esto" 24 .

Ricour verifica esta realidad ya conocida por todos los especialistas agustinianos. Las Confesiones, más allá de un relato autobiográfico, constituye un dilema existencial del autor. El hecho de la conversión tiñe el discurso filosófico-teológico ${ }^{25}$. Todas aquellas ideas, pensamientos o

22 B. Rey, La discrétion de Dieu (Éditions du Cerf, Paris, 1997), 17: "En effet, affirmer que Dieu crée la lumière, les astres, la terre et tout ce qu'elle renferme, et finalement l'humanité, c'est désacralise ces réalitatés: elles ne sont que des créatures [...] Dieu créateur, le peuple élu le distingue de tout l'ordre crée : il est totalement autre que sa création".

23 J. L. Marion, A lieu de soi l'approche de Saint Augustin (PUF, Paris, 2008), 31: "Nous admettrons d'abord et d'emblée le principe que pout saint Augustin la confessio se dédouble en confession des pèches et confession de louange".

24 San Agustín, Confesiones, XI, 1: "Numquid, Domine, cum tua sit aeternitas, ignoras, quae tibi dico, aut ad tempus vides quod fit in tempore? Cur ergo tibi tot rerum narrationes digero? Non utique ut per me noveris ea, sed affectum meum excito in te et eorum, qui haec legunt, ut dicamus omnes: Magnus Dominus et laudabilis valde. Iam dixi et dicam: amore amoris tui facio istuc".

25 O. Velásquez, “¿Qué confiesan las Confesiones?”, en Seminarios de filosofía 17-18 (2004-2005), 192-200: "Las Confesiones son la obra más plotiniana de Agustín, pero reflejan los dramáticos cambios que, en el transcurso de un siglo se habían suscitado en él y en el mundo a su alrededor. El gran pensador pagano dejaba una herencia ambivalente: la interioridad, espacio inteligible del hombre en que la divinidad podía ser hallada, continuaba conservando su lugar esencial; 
creencias deben pasar por el cedazo de la Escritura y de la fe revelada. Pero un hecho es indudable; el tono es tensional y a veces agobiante. Es así como el tema del tiempo es clave. Este traspasa el pensamiento de la época y el Kairos divino. Durante la época agustiniana confluyen dos tipos de pensamiento temporal. Uno de corte absolutista que piensa el tiempo como una realidad completa en sí misma (Estratón) y otra relacional que hace depender el tiempo de otra virtualidad. Ejemplo de ello es la relación tiempo-movimiento planteada por Aristóteles en su Física. Pero hay pensadores que combinan ambas posturas. Plotino afirmará que el tiempo es imagen móvil de la eternidad (Enn. I, 7), pero es una imagen que tiene su sede en el alma ${ }^{26}$.

Paul Ricœur afirmará que la especulación tiempo-eternidad ${ }^{27}$ en Agustín procura colocar: "[...] el tiempo bajo el horizonte de una idealímite [...] intensificar la experiencia misma de la distentio en el plano existencial [...] exigir a esta misma experiencia que se supere en la línea de la eternidad" 28 . El filósofo francés no desconoce el juego agustiniano de contraponer ambas realidades desde la revelación, ni el tono laudatorio del texto. Su intención radica en el "cómo" de ello. Revisemos brevemente cada una de estas explicaciones al dilema tiempo-eternidad:

\section{a) Idea limite}

La eternidad como idea límite implica dos hechos de la revelación. El primero es la Creación descrita por Agustín en los primeros párrafos del libro XI. Su inquietud no se aboca a la veracidad del hecho, sino al cómo

la desvalorización de la efigie y la forma exterior, en cambio, junto a ciertos sentimientos encontrados acerca de la individualidad, habría hecho imposible realizar un retrato como el que Agustín realiza de sí mismo en Confesiones. Podría resultar chocante hablar demasiado de sí mismo, por mucho que ya para Agustín los acontecimientos personales podían reflejar, con sorprendente lucidez, todo ese mundo espiritual en que se suponía habitaba la divinidad".

26 Cfr. Éditions du Centre National de la recherche scientifique, Le Temps chrétien de la fin de l'Antiquité au Moyen Age (IIIe-XIIIe siècles), (Paris 9-12 mars 1981, 1984).

27 A. Powter, "La relación tiempo-eternidad en el libro XI de las «Confesiones» de san Agustín” en Augustinus 53 (2008), 383-483.

28 P. Ricceur, Tiempo y narración I, 66: “le temps sous l'horizon d'une idée-limite [...] d'intensifier 1 , expérience même de la distentio au plan existential [...]cette expérience même a se surpasser en direction de l'éternité" (42). 
del mismo. En este momento aparece el segundo hecho de la economía de la salvación: la palabra. Pero no cualquier palabra que se pronuncia humanamente. Es el Verbo eterno del Padre: Jesucristo. El discurso del Génesis se complementa con el prólogo del Evangelista Juan. Ricœur juega con las palabras Verbum y verba para explicar este razonamiento. La primera permanece y la segunda pasa. Pero las epístolas paulinas señalan que Dios ha hecho todas las cosas por el Verbo. Esto también conduce a la perplejidad. El filósofo francés afirmará: “[...] esta asignación de un comienzo y de un fin por la razón eterna implica que esta conozca el momento cuando (quando) esa cosa ha tenido que comenzar y acabar" 29 . La palabra clave es razón eterna, la cual hace que las cosas sean o no sean. Lo anterior solo tiene sentido en una posible definición de eternidad: "Ni tú precedes temporalmente a los tiempos: de otro modo no precederías a todos dos tiempos. Mas precedes a todos los pretéritos por la celsitud de tu eternidad, siempre presente" 30 . Pensar la eternidad implica un siempre, a diferencia del tiempo que se reduce a una tríada contradictoria. El contexto hace presente el Timeo. El tiempo pareciera ser una creatura que se contradice con la nada. Es así como Ricœur presenta la tensión nada-ser o tiempo y eternidad como el eje fundante del obispo de Hipona.

\section{b) La experiencia intensificada ${ }^{31}$}

La ontología se esfuerza en hacer suya la revelación, pero la eternidad no puede ser vivida o vivible a diferencia del tiempo ${ }^{32}$. Por ello, Agustín en palabras de Ricœur transforma su Libro XI en una experiencia de queja. El tema fundamental es el deseo de Dios que desgarra el alma del hombre, pues existe una diferencia entre el Creador y la creatura expresada en esta dupla: tiempo y eternidad. Todos los comienzos laudatorios dirigidos a Dios no hacen otra cosa que expresar ese quebranto interior de

29 P. Ricceur, Tiempo y narración I, 70: “[...] cette assignation d'un commencement et d'une fin par la raison éternelle implique que celle-ci connaisse "le moment quand» (quando) cette chose a du commencer ou finir" (45).

30 San Agustín, Confesiones, XIII, 16: "Nec tu tempore tempora praecedis: alioquin non omnia tempora praecederes. Sed praecedis omnia praeterita celsitudine semper praesentis aeternitatis".

31 En este tema Ricœur recurre a Stanislas Boros y su ensayo sobre Las categorías de la temporalidad en san Agustín.

32 Cfr. P. Ricceur, Tiempo y narración I, 73-74. 
las Confesiones. Es así como la distentio animi deja el plano de las aporías temporales y se convierte en parte integrante del hombre.

\section{c) Jerarquización interna}

La no experiencia de la eternidad divina no es momentánea, sino recurrente. No significa repetición de la misma, sino profundidad de la caducidad temporal, "sin duda, era preciso confesar lo "otro" del tiempo para estar en condiciones de hacer justicia plena a la temporalidad humana y para proponerse no abolirla, sino profundizarla, jerarquizarla, desarrollarla, según planos de temporalización cada vez menos "distendidos" y más «extendidos, non secundum distentionem, sed secundum intentionen»" 33 .

Agustín intentará, con toda la sutileza que le permite su genio, salvaguardar la eternidad de $\operatorname{Dios}^{34}$ y la temporalidad humana. Ambas realidades se miran e intentan relacionarse, sin embargo, escapa a él una verdad. Existen puntos de fusión. Uno de ellos es el Verbo de Dios y otro son las expresiones artístico-litúrgicas ${ }^{35}$. Estas últimas adelantan algo de lo eterno. El discurso agustiniano siempre las presenta en contradicción. Es necesario salvaguardar la diferencia ontológica y olvidarse de la forma expresiva de dicha "contradicción". Ricœur da cuenta de este hecho mediante los tres postulados ya mencionados.

\subsection{El tiempo como intentio y distentio animi: la medida del tiempo}

La pregunta ontológica por la quidditas temporal cede al hecho humano de la temporalidad vivida ${ }^{36}$. La existencia está recubierta de una existencia temporal que no se puede explicar, pero que se vive en todo momento. Christoph Horn afirma respecto de lo anterior: "Parece como si aquí,

33 P. Ricceur, Tiempo y narración I, 79. "Sans doute fallait-il confesser l'autre du temps pour être en état de rendre pleine justice à la temporalité humaine et pour se proposer no de l'abolir mais de l'approfondir, de la hiérarchiser, de la déployer selon des niveaux des temporalisation toujours moins non secundum distentionem, sed secundum intentionen" (53).

34 Cfr. E. Gisson, Introduction à l'étude de saint Augustin (Libraire philosophique J. Vrin, París 1949), 246 ss.

35 C. Boureux, "La liturgie comme manière d'habiter l'espace et le temps" en Théophilyon, 15(2010), 27-50.

36 Cfr. P. Ricceur, Tiempo y narración I, 42. 
al final del pensamiento antiguo, por primera vez se distinguiera entre tiempo objetivo y tiempo subjetivo" 37 . Ricœur centrará agudamente sus afirmaciones en las preguntas vitales de Agustín. La reflexión especulativa supone el fenómeno mismo del tiempo. Por ello, una posible respuesta a la cuestión del cronos solo es capaz de generar un sinnúmero de nuevas disquisiciones. Así, la llamada solución psicológica atribuida a Agustín contiene una inviabilidad de orden racional dada por su lógica argumentativa. Este dilema es descrito con agudeza por nuestro filósofo francés al señalar: "En mi libro será constante la tesis de que la especulación sobre el tiempo es una cavilación inconclusa a la que solo responde la actividad narrativa. No porque esta resuelva por suplencia las aporías; si las resuelve, es en sentido poético y no teorético" ${ }^{38}$. La palabra clave es aporía. Pero ¿a qué tipo de aporía se refiere Ricœur al dialogar con Agustín? Revisemos las grandes ideas agustinianas comentadas agudamente por el filósofo francés.

La interrogante ¿acaso se puede mensurar el tiempo? tiene sentido en otra interrogante fundamental ¿qué es el tiempo? Pareciera obvio tener en la mente tal premisa. Pero en el horizonte agustiniano ello implica una ontología desgarradora: “¿Qué es entonces el tiempo? Si nadie me lo pregunta, lo sé, y si trato de explicárselo a quien me lo pregunta, no lo sé"39. El lamento agustiniano responde al escepticismo de su época. Saranyana describe esta situación con la siguiente afirmación: "San Agustín estima, por consiguiente, que el mundo de la experiencia impone cierta suma de certidumbres. Contra la evidencia de la realidad del universo sensible no hay -según él- escepticismo que valga" ${ }^{*}$. De allí que la relación del tiempo y de su medida sean relevantes en su pensamiento. Ricœur hablará de la paradoja del ser y del no $\operatorname{ser}^{41}$. Este apun-

37 C. Horn, Agustín de Hipona (IES, Santiago 2012), 105.

38 P. Ricceur, Tiempo y narración I, 43: "Ce sera une thèse permanente de ce libre que la spéculation sur le temps est une rumination inconclusive à laquelle seule réplique l'activité narrative. Non que celle-ci résolve par suppléance les apories. Si elle les résout, c'est en un sens poétique et no théorétique du terme” (21).

39 San Agustín, Confesiones, XIV, 17: "Quid est ergo tempus? Si nemo ex me quaerat, scio; si quaerenti explicare velim, nescio".

40 J. I. Saranyana, La filosofía medieval (Eunsa, Pamplona 2007), 67. Cfr. C. Kirwan, Augustine against the Skeptics- The Skeptical Tradition (University of California Press, Berkeley, 1983), 205-224.

41 Cfr. P. Ricceur, Tiempo y narración I, 45. 
tará al meollo de la cuestión ¿cómo es posible dar cuenta de la medida del tiempo? Solo el lenguaje es capaz de ello. Por ello, Agustín describe la acción temporal del hombre mediante ejemplos significativos. La brevedad y la largueza dan cuenta de la expectación y de la memoria. De allí que el análisis del Doctor de la Gracia se sitúe en definir presente, pasado y futuro:

"Y, sin embargo, Señor, sentimos los intervalos de los tiempos y los comparamos entre sí, y decimos que unos son más largos y otros más breves. También medimos cuánto sea más largo o más corto aquel tiempo que este, y decimos que este es doble o triple y aquel sencillo, o que este es tanto como aquel. Ciertamente nosotros medimos los tiempos que pasan cuando sintiéndolos los medimos; mas los pasados, que ya no son, o los futuros, que todavía no son, ¿quién los podrá medir? A no ser que se atreva alguien a decir que se puede medir lo que no existe" ${ }^{\prime 2}$.

Por su parte, Paul Ricœur dará cuenta de la dinámica de la acción agustiniana. Verbos como sentimus, comparamus o metimur aluden a la experiencia sensible, y el autor de Confesiones se ofusca en la quididad del tiempo. La pregunta del cómo se manifiesta el tiempo sucede a la del qué es ${ }^{43}$. Por ello:

"El discurso de Agustín sobre el carácter enigmático del tiempo se podría remontar a Plotino. El tiempo, un fenómeno cotidiano bien conocido, se esconde [...] Con todo, está claro que eternidad significa reposo y calma, y movimiento un proceso inquieto [...] existe una dificultad en el hecho de que en el transcurso del tiempo lo futuro pasa a ser pretérito" ${ }^{34}$.

42 San Agustín, Confesiones, XVI, 21: "Et tamen, Domine, sentimus intervalla temporum et comparamus sibimet et dicimus alia longiora et alia breviora. Metimur etiam, quanto sit longius aut brevius illud tempus quam illud et respondemus duplum esse hoc vel triplum, illud autem simplum aut tantum hoc esse quantum illud. Sed praetereuntia metimur tempora, cum sentiendo metimur; praeterita vero, quae iam non sunt, aut futura, quae nondum sunt, quis metiri potest, nisi forte audebit quis dicere metiri posse quod non est? Cum ergo praeterit tempus, sentiri et metiri potest, cum autem praeterierit, quoniam non est, non potest".

43 Cfr. P. Ricceur, Tiempo y narración I, 49. Cfr. W. Beierwaltes, Platonismus im Christentum, (Frankfurt am Main, Vittorio Klostermann 1998). Cfr. W. Beierwaltes, Identität und Differenz (Frankfurt, Klostermann 1980).

44 C. Horn, Agustín de Hipona, 108. 
La solución de los tres presentes no hace otra cosa que transformar lo qué es en una característica y no en algo esencial. Por lo tanto, lo accesorio requiere de una matriz fundamental. El tiempo requiere asentarse en un lugar. Diríamos en un dónde.

\subsection{La memoria y la expectación}

Ricœur poco a poco va desentrañando la lógica argumentativa de Agustín. De esta manera, señala tres preguntas fundamentales: ¿Qué es el tiempo?, ¿`ómo se manifiesta?, ¿dónde está? En la trama argumentativa del libro XI de las Confesiones. La comprensión de dicha forma mentis está dada por el tono himnódico del Doctor de la Gracia. Este pareciera tener dos motivaciones. En primer lugar, pedir auxilio a la divinidad, y en segundo lugar, dar cuenta de nuevas aporías, preguntas y cuestionamientos. Es indudable que para responder a la cuestión del dónde se debe profundizar en dos palabras claves. El mismo Ricœur señalará: "(...) las nociones de narración y de previsión dentro del marco de la cuestión dónde. Narración -diremos- implica memoria y previsión, espera. Pero, ¿qué es recordar?" 45 . Todo lenguaje se fundamenta en signos. Muchos de ellos pasan desapercibidos, pero otros dejan su huella en el hombre. La memoria ${ }^{46}$ juega un rol de asidero de este pasado de impresiones actuales. Agustín no puede dejar de lado la historia salutis del pueblo de Israel y de la Iglesia, pero debe justificar al Cristo que ha de venir por medio de la expectación. El presente dilataría o contraería. Nuestro filósofo francés señalará que es una solución elegante pero laboriosa. Tanto la huella pretérita o el signo premonitorio requieren de un dónde. Agustín Afirmará:

"Pero lo que ahora es claro y manifiesto es que no existen los pretéritos ni los futuros, ni se puede decir con propiedad que son tres los tiempos: pretérito, presente y futuro; sino que tal vez sería más propio decir que los tiempos son tres: presente de las cosas pasadas, presente de las cosas presentes y presente de las futuras. Porque estas son tres cosas que existen de algún modo en el alma, y fuera de ella yo no veo que existan:

45 P. Ricceur, Tiempo y narración I, 49: “[...] les notions de narration et de prévision. Narration, dirons-nous, implique mémoire, et prévision implique attente. Or qu'est-ce que se souvenir?” (26-27).

46 Cfr. M. Yoshishika, "Significado de memoria en las Confesiones de san Agustín” en Augustinus 31 (1986), 213-220. 
presente de cosas pasadas (la memoria), presente de cosas presentes (visión) y presente de cosas futuras (expectación)" ${ }^{47}$.

Enclave de lo anterior es el término "anima”. El paso de lo ontológico al espíritu humano implica una nueva pregunta: ¿Cómo caracterizar el tiempo humano? Pues la interrogante ¿qué es el tiempo humano? ${ }^{48}$, no tiene sentido. Lo mensurable aparece nuevamente a la palestra conectada al movimiento de los astros y al concepto de día. Pareciera que Agustín discutiese con los filósofos anteriores a él y nuevamente centrase su atención en una cosmología ontológica. Pero es la idea del Dios creador la que prevalece en su horizonte. ¿Acaso el movimiento de los astros es el tiempo? ¿Dios no podría acelerar ese movimiento, cambiando los días, los meses y los años en su duración? Dios ha creado los astros para marcar el tiempo, como señala el libro del Génesis. Paul Ricœur señala que este momento es decisivo ${ }^{49}$. Hay un giro. Agustín lo formula de la siguiente forma: "Veo, pues, que el tiempo es una cierta distensión. Pero ¿lo veo o es que me figuro verlo?"50. En palabras de Ricœur la distensión explica la tríada del presente que se ve, se recuerda y se espera. Sin embargo, la coordenada de sentido es el espíritu humano ${ }^{51}$. La mensurabilidad del tiempo no debe nada al movimiento exterior, se escapa a él. Aquí se encuentra la interpretación y crítica ricqueriana de Agustín ${ }^{52}$.

\subsection{Intentio-distentio}

El pensamiento agustianiano, pese a centrarse en el presente y en sus extensiones temporales, solo puede hacer consciente el pasado a través del lenguaje. Preguntas como ¿cuánto tiempo hace que salimos de Tagaste?, nos remiten a una acción pretérita. Más aún, ejemplos como la

47 San Agustín, Confesiones, XVI, 20, 26: "Quod autem nunc liquet et claret, nec futura sunt nec praeterita, nec proprie dicitur: tempora sunt tria, praeteritum, praesens et futurum, sed fortasse proprie diceretur: tempora sunt tria, praesens de praeteritis, praesens de praesentibus, praesens de futuris. Sunt enim haec in anima tria quaedam et alibi ea non video, praesens de praeteritis memoria, praesens de praesentibus contuitus, praesens de futuris exspectatio".

48 Cfr. P. Ricceur, Tiempo y narración I, 53.

49 Cfr. P. Ricceur, Tiempo y narración I, 57.

50 San Agustín, Confesiones, XVI, 23, 30. "Video igitur tempus quamdam esse distentionem. Sed video?".

51 Cfr. P. Ricceur, Tiempo y narración I, 58.

52 Cfr. P. Riccur, Tiempo y narración I, 61. 
voz, la cual empieza a sonar o cesa totalmente, patentiza una situación compleja: "En cuanto al tiempo presente, ¿`cómo lo medimos, si no tiene espacio? Lo medimos ciertamente cuando pasa, no cuando es ya pasado, porque entonces ya no hay qué medir" ${ }^{53}$. Pero Ricœur apunta al meollo del asunto. Agustín señala: "Porque pasando se extendía (tendebatur) en cierto espacio de tiempo en que podía ser medida, por no tener el presente espacio alguno" 54 . La palabra fundamental es el verbo "extender" y no "pasar". Este último no sitúa en la dimensión ontológica del no ser. En cambio, el primero implica permanencia. Sin duda: "La noción de distentio animi no ha recibido lo que corresponde hasta que no haya contrastado la pasividad de la impresión con la actividad del espíritu en direcciones opuestas [...]. Solo un espíritu así, diversamente extendido, puede distenderse" ${ }^{55}$. En consecuencia, el espíritu humano permite un tránsito activo mediante el presente. Este es quien atiende, espera y recuerda. Por ello, el tiempo encuentra su inflexión más mínima en el presente como punto de paso y más alto en la misma acción de pasar:

"Supongamos que voy a recitar un canto sabido de mí. Antes de comenzar, mi expectación se extiende a todo él; mas en comenzándole, cuanto voy quitando de ella para el pasado, tanto a su vez se extiende mi memoria y se distiende la vida de esta mi acción en la memoria, por lo ya dicho, y en la expectación, por lo que he de decir. Sin embargo, mi atención es presente, y por ella pasa lo que era futuro para hacerse pretérito. Lo cual, cuanto más y más se verifica, tanto más, abreviada la

53 San Agustín, Confesiones, XXI, 27: "Dixi ergo paulo ante, quod praetereuntia tempora metimur, ut possimus dicere duplum esse hoc temporis ad illud simplum aut tantum hoc quantum illud et si quid aliud de partibus temporum possumus renuntiare metiendo. Quocirca, ut dicebam, praetereuntia metimur tempora, et si quis mihi dicat: "Unde scis?», respondeam: «Scio, quia metimur, nec metiri quae non sunt possumus, et non sunt praeterita vel futura». Praesens vero tempus quomodo metimur, quando non habet spatium? Metimur ergo, cum praeterit, cum autem praeterierit, non metitur; quid enim metiatur, non erit".

San Agustín, Confesiones, XXVII, 34: "Praeteriens enim tendebatur in aliquod spatium temporis, quo metiri posset, quoniam praesens nullum habet spatium".

55 P. Ricceur, Tiempo y narración I, 61: "La notion de distentio animi n'a pas reçu son du tant qu'ont n'a pas contrasté la passivité de l'impression avec l'activité d'un esprit tendu en des directions opposées [...] la mémoire et l'attention. Seul un esprit ainsi diversement tendu peut être distendu" (37). 
expectación, se alarga la memoria, hasta que se consume toda la expectación, cuando, terminada toda aquella acción, pasare a la memoria" ${ }^{\prime 5}$.

Ricœur señalará que la distensión agustiniana se concibe como un contraste entre tres tensiones, como una dialéctica de la espera y de la expectación; y como un desfase o no coincidencia de las tres modalidades de acción ${ }^{57}$. Agustín reduce la extensión del tiempo en toda su complejidad lingüística a la distensión del espíritu humano que canta y en la misma acción todo se funde. Presente, pasado y futuro se desfasan, concuerdan y se separan en el mismo actuar del Espíritu humano. Pese a ello, Agustín no descubre que la tensión puede disiparse en el mismo hecho del relato. La verticalidad de la eternidad sofoca la horizontalidad del tiempo ${ }^{58}$. La insistencia de un alma vuelta a Dios es un ejemplo clave de este dilema ${ }^{59}$.

\section{Hallazgos E intuiciones}

El primer tomo de Temps et récit constituye una recepción desde la etimología misma de la palabra: recipere. Paul Ricœur hace suyo el pensamiento agustiniano, pero a la vez toma distancia de él con una tónica de profundo respeto y simpatía. Intenta descubrir las categorías que sustentan la forma mentis del Doctor de la Gracia. Esta manera de actuar no pretende sintetizar ni mucho menos desmembrar el edificio de las Confesiones. Su afán primordial es interrogarse sobre las aporías que nacen de

56 San Agustín, Confesiones, XXVIII, 38: "Dicturus sum canticum, quod novi: antequam incipiam, in totum exspectatio mea tenditur, cum autem coepero, quantum ex illa in praeteritum decerpsero, tenditur et memoria mea, atque distenditur vita huius actionis meae in memoriam propter quod dixi et in exspectationem propter quod dicturus sum; praesens tamen adest attentio mea, per quam traicitur quod erat futurum, ut fiat praeteritum. Quod quanto magis agitur et agitur, tanto breviata exspectatione prolongatur memoria, donec tota exspectatio consumatur, cum tota illa actio finita transierit in memoriam. Et quod in toto cantico, hoc in singulis particulis eius fit atque in singulis syllabis eius, hoc in actione longiore, cuius forte particula est illud canticum, hoc in tota vita hominis, cuius partes sunt omnes actiones hominis, hoc in toto saeculo filiorum hominum, cuius partes sunt omnes vitae hominum".

57 Cfr. P. Ricceur, Tiempo y narración I, 62-63.

58 Cfr. P. Ricceur, Caminos de reconocimiento, 156. Cfr. J. Nabert, Le désir de Dieu (Éditions du Cerf, Paris 1996), 73ss.

59 Cfr. CH. TaYlor, Las fuentes del y la construcción de la identidad moderna (Paidós, Barcelona 2006), 184-185. 
la estructura discordante-concordante del tiempo ${ }^{60}$. El tiempo es ambiguo cuando no posee un modus operandi. Este se lo proporcionará el relato ${ }^{61}$.

El tomo III de Temps et récit funda una opinión personal de Paul Ricœur sobre la lógica temporal de Agustín, pero no con un afán destructivo ni mucho menos anacrónico. Pues entre ambos autores surge una separación de varios siglos. Revisemos las grandes coyunturas planteadas por el filósofo francés:

\subsection{Cosmología y psicología}

Ricœur señalará: "El principal fracaso de la teoría agustiniana es el no haber logrado sustituir la concepción cosmológica del tiempo por la psicológica"62. Agustín intenta pasar del concepto de tiempo a la realidad humana del mismo. Por ello, hace convivir dos realidades que no se excluyen aunque no se implican satisfactoriamente. Nuestro autor francés acotará: "Mi convencimiento es que la dialéctica entre la intensio y la distentio animi es incapaz de engendrar por sí sola ese carácter imperioso del tiempo; y que paradójicamente contribuye a ocultarlo"63. Agustín dedica largos pasajes del libro XI a solicitar de Dios un auxilio a sus cavilaciones. El género laudatorio, imprecatorio o elegíaco se suceden en un gemido agobiante. La misma trama es la posibilidad de solucionar esta ambigüedad. El tiempo se muestra y se esconde en la medida de su mensurabilidad. El Padre de la Iglesia intenta alejar de sus propósitos la posibilidad de unir tiempo con movimiento, a diferencia de Aristóteles. Pero pasa de largo algo tan fundamental: son realidades distintas ${ }^{64}$.

\subsection{Espíritu - Mundo}

Agustín considera como único acceso válido al tiempo y a su medida el Espíritu humano y no concibe una contraparte con el "mundo".

60 Cfr. P. Ricceur, Tiempo y narración III, 641.

${ }^{61}$ Cfr. E. Silva, "Poética del relato y poética teológica: aportes de la hermenéutica filosófica de Paul Ricœur" en Anales de la Facultad de Teología 56 (Santiago de Chile, 2000).

62 P. Ricceur, Tiempo y narración III, 643: "L'échec majeur de la théorie augustinienne est de n'avoir pas réussi à substituer une conception psychologique du temps à une conception cosmologique"(19).

63 P. Ricceur, Tiempo y narración III, 643:

64 Cfr. P. Ricceur, Tiempo y narración III, 645. 
Este puede ser entendido en un sentido amplio (Naturaleza, otro, etc.). Ricœur recuerda las principales ideas de la Física II de Aristóteles: "La naturaleza es un principio (arjé) y una causa (aitía) de movimiento y de reposo para la cosa en la que reside inmediatamente, por esencia y no por accidente [...] Que el tiempo no es el movimiento [...] Aristóteles lo había dicho antes que Agustín" ${ }^{65}$, pues con ello resalta que la pretensión de fundar la medida del tiempo en el Espíritu se desvanece en el pasaje anterior. La percepción temporal según Aristóteles lo considera como el número de movimiento según el antes y el después. La phisis reemplaza el alma.

\subsection{Las aporías - Las posibles respuestas}

Nuestro autor dedica largas páginas a presentar los quiebres en el pensamiento aristotélico, pero concluye: "Estas aporías que concluyen nuestra breve incursión en la filosofía aristotélica del tiempo, no están destinadas a servir de apología indirecta de la "psicología» agustiniana. Sostengo, al contrario que Agustín no ha refutado a Aristóteles y que su psicología no puede sustituir -sino solo añadirse- a la cosmología" ${ }^{66}$.

Ahora bien, Ricœur sostendrá que la misma crítica se da al pensar el "instante" aristotélico como el "presente" agustiniano. Ambos carecen de algo:

"Y sin embargo, las dificultades propias de una y de otra perspectiva exigen que las dos sean conciliadas; a este respecto [...] no es posible afrontar el tiempo por un solo extremo, el alma o el movimiento. La sola distensión del alma no puede producir la extensión del tiempo así como el solo dinamismo del movimiento no puede engendrar la dialéctica del triple presente" 67 .

65 P. Ricceur, Tiempo y narración III, 647: "La nature est un príncipe (arkhè) et une cause (aitia) de mouvement et de respos pour la chose en laquelle elle réside immédiatement, par la essence et non par accident [...] Que le temps pourtant ne soit pas le mouvement [...] Aristote l'a dit avant Augustin" (23).

66 P. Ricceur, Tiempo y narración III, 654: “Ces apories qui terminent notre brève incursion dans la philosophie aristotélicienne du temps ne sont pas destinées à servir d'apologie indirecte en faveur de la "psychologie» augustinienne. Je tiens contraire qu'Augustin n'as pas réfuté Aristote et que sa psychologie ne peut se substituer - mais peut seulement s'ajouter- à une cosmologie" (29-30).

67 P. Ricceur, Tiempo y narración III, 661: "Et pourtant, les difficultés propres à l'une à l'autre perspective exigent que les deux perspectives soient conciliées (il n'est 
La teoría de la recepción ${ }^{68}$ supuso un cambio a la hora de enfrentarse a un texto, al considerar al lector o receptor como punto de referencia histórica para el estudio de una obra. En general, tanto el autor como la materialidad ocupaban un lugar preponderante. Estas tres duplas: cosmología-psicología, espíritu-mundo y aporía-respuesta, constituyen una lectura válida y profunda de nuestro autor francés. El Dios de Agustín, la antropología de las Confesiones y el devenir pensado filosóficamente y teológicamente son pasados por un cedazo muy fino. Detengámonos en una conclusión que dirima el título de esta ponencia.

\section{Conclusión}

La posición de Agustín frente al tema del tiempo se reviste de cierta negatividad, incluso poéticamente lo presenta como inalcanzable en su quidditas, pero garante de una realidad opuesta. Esta es la eternidad ${ }^{69}$. Por ello, el tiempo se deshace en palabras y experiencias humanas ${ }^{70}$; pero no tiene un dónde vivencial, sí uno teológico y uno filosófico: el alma. Por su parte, Paul Ricœur y su insistencia sobre las aporías del tiempo agustiniano revela "la aparente imposibilidad de una fenomenología pura del tiempo [...] la poética del relato puede responder por una parte, a la aporética de la temporalidad"71. Por ello, la recepción del filósofo francés no es una mera utilización de una fuente de estudio, sino una búsqueda de significatividad. El lenguaje cobrará un papel relevante, pues constituye una mediación entre la distentio animi agustiniana y el mithos trágico de Aristóteles. Sin embargo, un estudio más profundo del tema de la interioridad en el Doctor de la Gracia contribuiría a matizar dichos postulados. Así como una revisión de otras obras de Paul Ricœur, ahondaría en estos tópicos y contribuiría a dilucidar el enigma

pas possible d'attaquer le problème du temps par une seule extrémité, l'âme ou le mouvement. La seule distension de l'âme ne peut produire l'extension du temps; le seul dynamisme du mouvement ne peut engendrer la dialectique du triple présent" (35-36).

68 Cfr. H. G. Gadamer, Verdad y método: fundamentos de una hermenéutica filosófica, (Sígueme, Salamanca 1977).

69 Cfr. G. Madec, Le Dieu d'Augustin (Édition du Cer, París 2000), 85-93.

70 Cfr. A. Pic, "Le temps selon saint Augustin" en Maxence Caron (ed.), Les Cahiers d'histoire de la philosophie: saint Augustin (Éditions du Cerf, Paris 2009), 256 ss.

71 I. Bochet, Variations contemporaines sur le thème augustinienne: l'énigme du temps, 539-530. 
La recepción del pensamiento agustiniano sobre el tiempo en Temps et récit de Paul Ricœur 459

de la temporalidad. Pero ello escapa a nuestro estudio. Sin embargo, en Temps et récit existe una apuesta por una percepción fenomenológica del sujeto, donde no solo se considera el aspecto cronológico, sino un "hacer presente" el tiempo de manera existencial.

Una poética del lenguaje con sus juegos verbales puede dar cuenta del obrar, del kairos y de la semántica humana ${ }^{72}$. Allí se encuentra la apuesta ricqueriana.

V. Balaguer, La interpretación de la narración. Teoría de Paul Ricour (EUNSA, Navarra 2002), 113 ss. 
Resumen: El paso de una concepción ontológica del tiempo a una comprensión psicológica del mismo es, sin duda, el gran aporte de san Agustín de Hipona. Sus intuiciones y preguntas son abordadas desde la modernidad por Paul Ricœur. Sin embargo, la recepción de la temporalidad tiene presente otras variables que problematizan dicha cuestión. Una de ellas es su vivencia concreta.

El filósofo francés en su libro Temp et récit rescata aquellos elementos que permiten reformular la pregunta: ¿Qué es el tiempo? No desde la abstracción, sino desde su actualización fáctica. Este artículo pretende establecer un nexo entre ambos autores desde la materialidad propia del texto. El tiempo se vive humanamente y no se encuentra al margen del sujeto.

Palabras clave: Agustín de Hipona, Paul Ricœur, sujeto, temporalidad y Temps et récit.

Abstract: The pass from an ontological concept of time to a psychological comprehension of the same, is without a doubt, the big contribution of Agustine of Hippo. His intuitions and questions are approached by Paul Ricœur from a modern point of view. Never the less, the reception of temporality has other variables present, which pose a difficulty to this issue. One of them is it's concrete experience. The French Philosopher in his book "Time and Narrative" rescues those elements that permit the reformulation of the question: What is time? Not from abstraction, but based on facts. This article pretends to establish a connection between both authors from the physical substance of the text. Time is lived humanely and is not apart from the individual.

Keywords: Agustine of Hippo, Paul Ricœur, subject, temporality and Time and Narrative. 